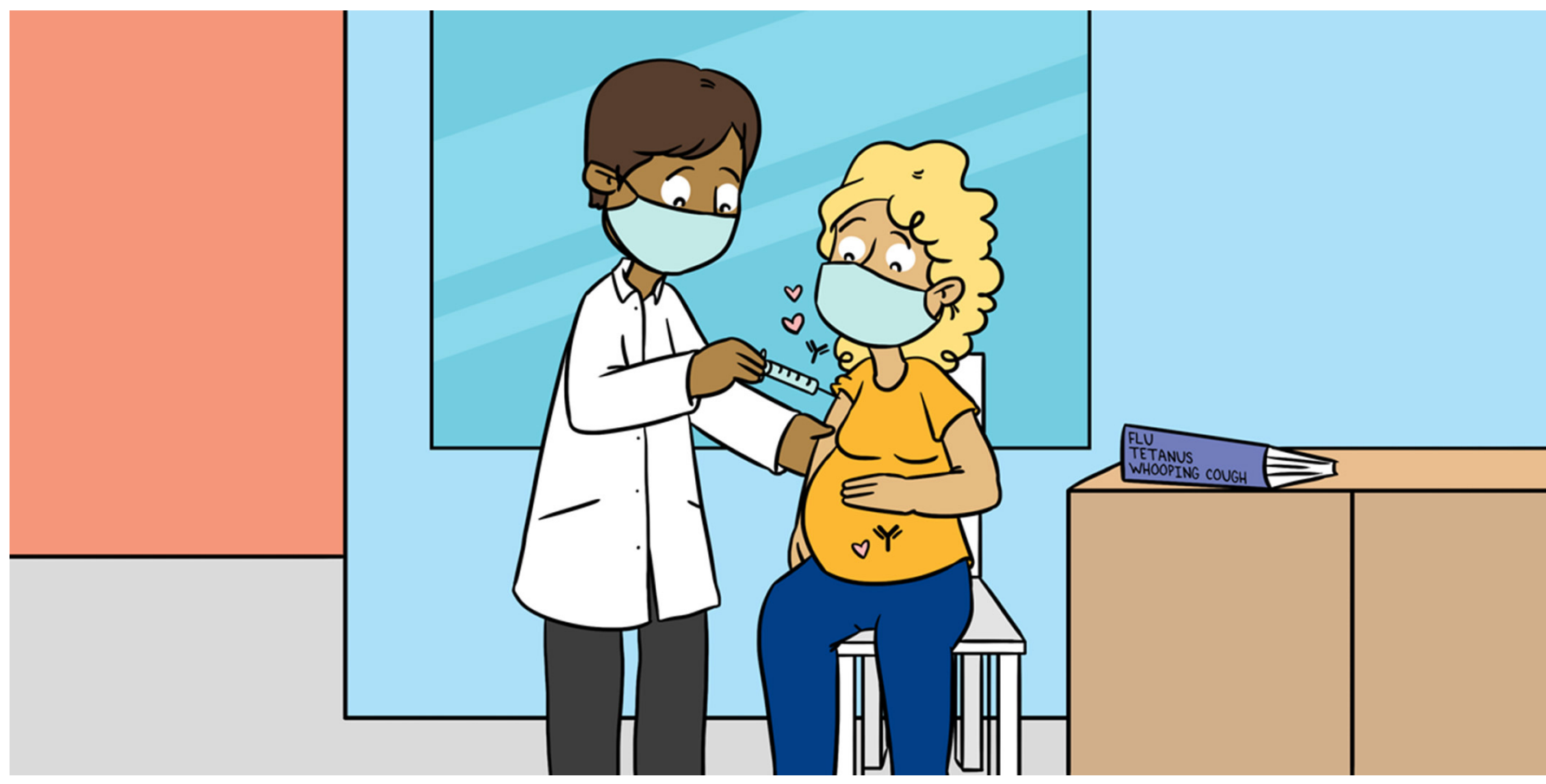

\title{
VACCINATION OF PREGNANT WOMEN: PROTECTING BABIES EVEN BEFORE BIRTH!
}

\section{Kirsten Maertens, Marjolein Orije and Elke Leuridan*}

Centre for the Evaluation of Vaccination, Vaccine \& Infectious Diseases Institute, University of Antwerp, Antwerp, Belgium

YOUNG REVIEWER:

LILI

AGE: 10
Vaccines protect humans against microorganisms that cause disease. Usually, vaccines are given to infants, toddlers, or older children at regular intervals. For example, you probably know about the tetanus vaccine, which is given to you when you are hurt, or beforehand, to protect you from disease in case you get hurt. Maternal immunization means vaccination of a woman during pregnancy. This can protect the pregnant woman and her unborn child from disease, and can also protect the new-born baby. The protection is provided by antibodies, which are substances made in the mothers' body after vaccination, and are transported through the placenta and the breastmilk to the baby. Some vaccines are advised to be taken during pregnancy and, in the future, some vaccines might even be specifically designed to be used during pregnancy. This article will explain how vaccination during pregnancy works. 


\section{VACCINE}

A substance given to a person to prevent a specific infectious disease caused by a specific microorganism.

\section{MATERNAL}

IMMUNIZATION

Vaccination of a woman during pregnancy, which can protect both the woman and her unborn baby. Babies continue to be protected for a few months after birth.

\section{WHY DO WE VACCINATE DURING PREGNANCY?}

Vaccines are substances that can protect your from infectious diseases caused by microorganisms. Many vaccines are safe for everyone and can even be used in pregnant women. Maternal immunization means vaccination of a woman during pregnancy. This type of vaccination can protect the pregnant woman and her unborn child from certain diseases, and can also protect the new-born baby for several months after birth.

There are a few vaccines that are already used during pregnancy, including vaccines against flu, tetanus, and whooping cough (pertussis) [1, 2]. These vaccines can often be received at the pharmacy. Flu, tetanus, and pertussis vaccines are given to pregnant women because the diseases they protect against are particularly risky, either for pregnant women, their unborn babies, or for new-born babies.

\section{VACCINES USED IN PREGNANCY}

The first vaccine to be approved for use in pregnancy was the tetanus vaccine. Tetanus is caused by a bacterium called Clostridium tetani that lives in dirt and in soil, as well as on rusty surfaces. When you injure your foot on a rusty nail, for example, you could get tetanus. The bacterium Clostridium tetani causes neonatal tetanus disease, which means tetanus disease of the new-born baby, and often leads to death. Pregnant women are advised to get the tetanus vaccine to protect themselves and their new-borns from this disease.

A second vaccine that is recommended during pregnancy is the whooping cough vaccine. This vaccine is recommended in pregnancy because whooping cough disease is more severe for babies in their first weeks of life, often leading to hospitalization and even death. The bacterium causing whooping cough is called Bordetella pertussis. Neither the pregnant woman nor the unborn baby are in danger when they are infected by Bordetella pertussis, yet the new-born baby is! Vaccination during pregnancy can protect new-born infants from birth until they are old enough to be vaccinated themselves.

Last, the flu vaccine is recommended in pregnancy mainly because pregnant women can become more severely ill if they get flu, which is caused by the influenza virus. Contracting flu during pregnancy can endanger the pregnant women and her unborn child.

In addition to these three recommended vaccines, several other vaccines can be used in pregnancy if the pregnant woman has a specific individual risk. For example, when a pregnant woman must travel and needs vaccines to be protected against diseases present in other countries, certain other vaccines are safe to 
Figure 1

When a vaccine is given to a pregnant woman, she makes antibodies. The antibodies are transported through the placenta to the unborn baby and remain in the baby's blood, where they can provide protection before the baby is born and during the first few months after birth.

\section{ANTIBODIES}

Molecules produced by the body to attack disease-causing organisms.

\section{IMMUNE SYSTEM}

The system in your body protecting you against disease, based on biological processes.

\section{PLACENTA}

An organ that grows in the womb during pregnancy, which allows the baby to get nutrients and antibodies from the mother's blood.

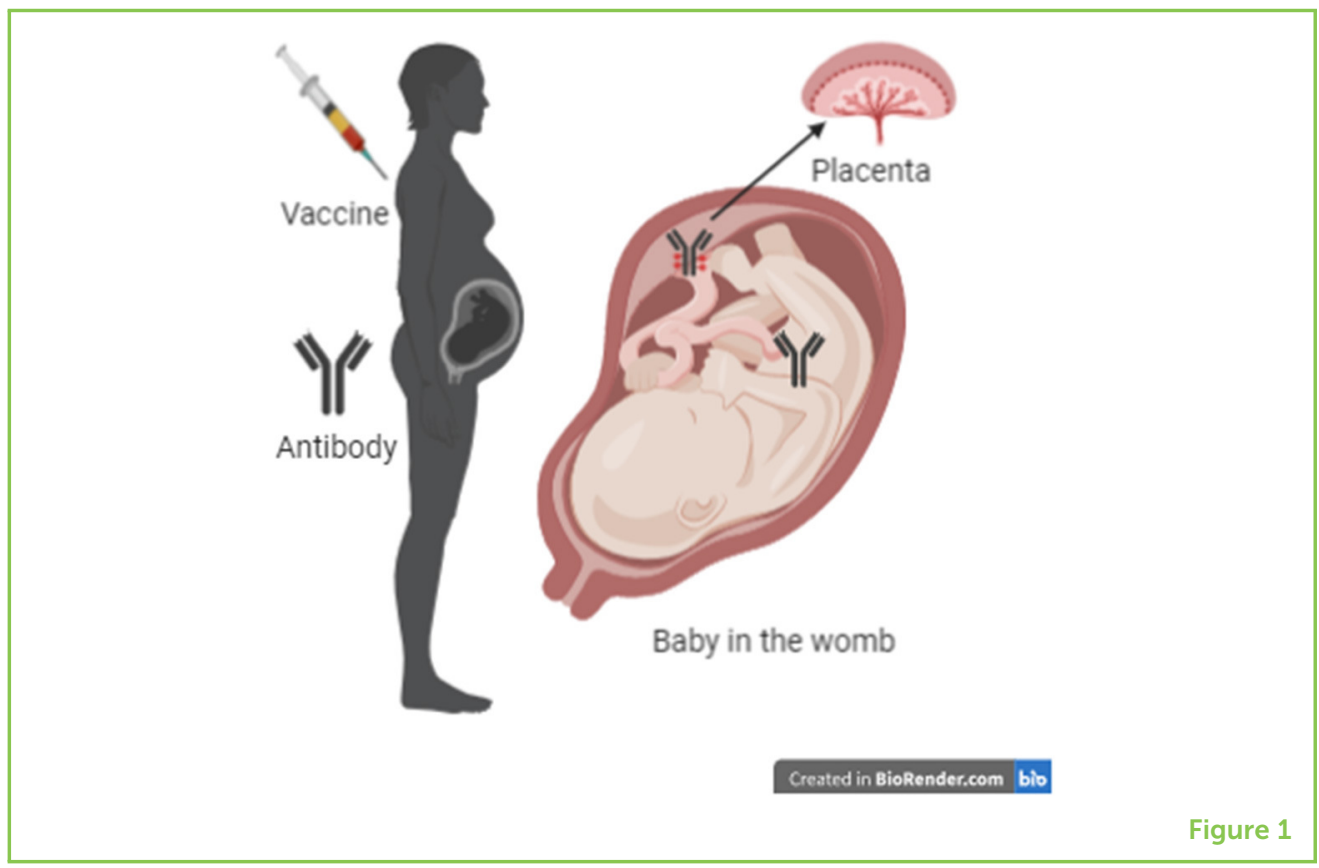

give during pregnancy, such as meningococcal vaccines and hepatitis vaccines.

\section{HOW DOES MATERNAL IMMUNIZATION WORK?}

When we give a person a vaccine, the person will make antibodies. Antibodies are molecules made by the immune system, and they are one of the body's weapons against disease-causing organisms. When we vaccinate a pregnant woman, she will produce a lot of antibodies. These antibodies will not only protect her from the disease, they will also be transported through the placenta to the unborn child (Figure 1). The placenta is an organ that grows in the womb during pregnancy and its role is to provide the baby with blood containing nutrients to help the baby grow. The placenta also has a special transport mechanism that actively transports antibodies from the mother's blood to the baby. In fact, if the pregnancy lasts the full 40 weeks, the baby will have higher levels of antibodies than the mother!

Other antibodies produced in the mother are specifically designed to be transported to the baby through the breastmilk (Figure 2). These antibodies can provide additional protection to the baby during the first weeks and months after birth, when the mother is breastfeeding her child. The amount of maternal antibodies transferred to the new-born through both the placenta and the breastmilk depends on the timing of vaccination during pregnancy [3], the health of the mother and their placenta, and the amount of antibodies the pregnant woman has. For maximum transfer of maternal antibodies to the unborn child, the concentration of antibodies in the mother's 


\section{Figure 2}

When a vaccine is given to a pregnant woman, she makes antibodies that end up in her breastmilk. When she breast feeds her new-born child, those antibodies are transferred into the baby.

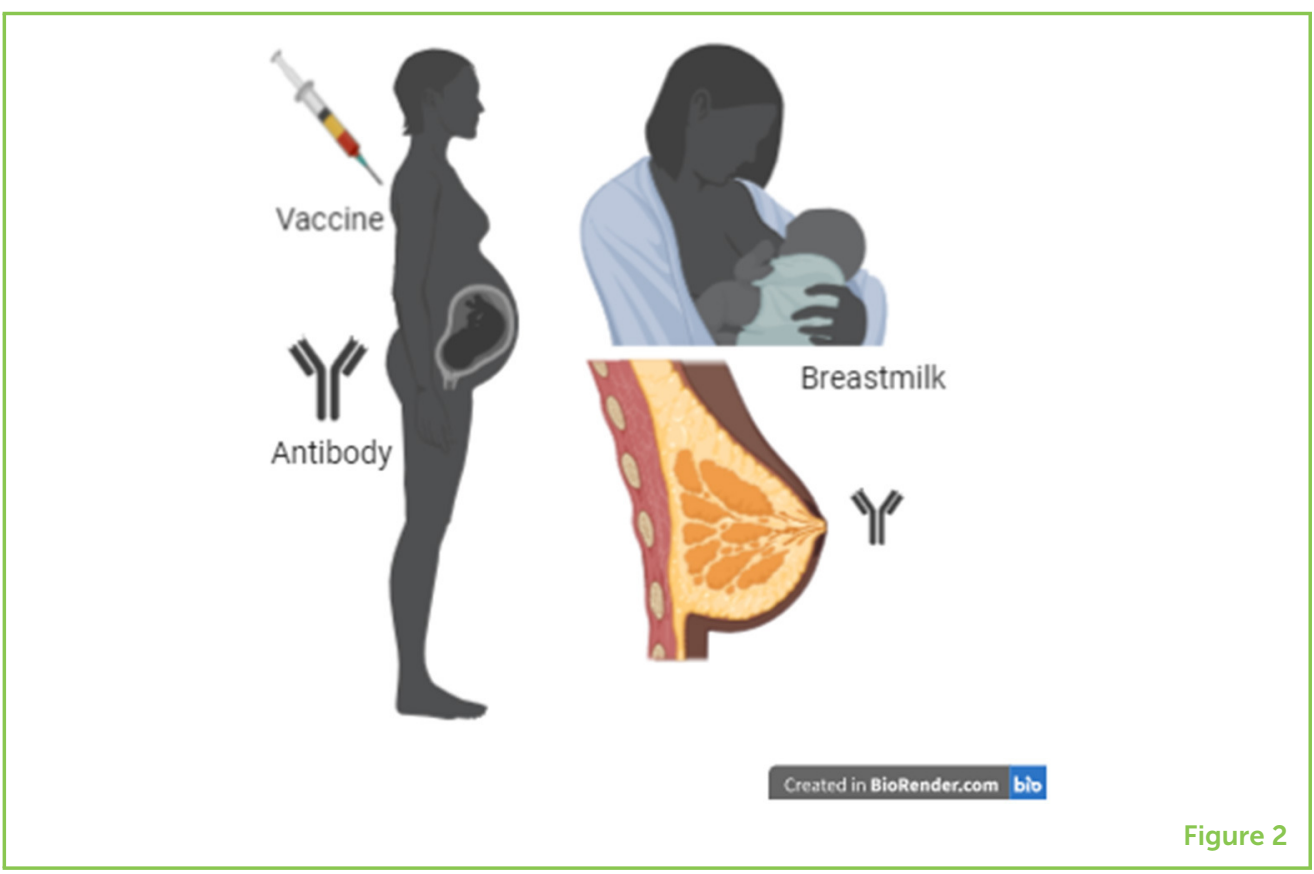

blood should be high, which means that vaccination should be performed well in time, and thus preferably not near the end of the pregnancy.

Maternal antibodies do not last forever in babies. They decrease over 6-12 months after birth. But that is OK, because maternal antibodies only need to protect babies until they are old enough to receive their own vaccines $[4,5]$.

\section{IS IT SAFE TO VACCINATE DURING PREGNANCY?}

Vaccination during pregnancy is very safe. Many studies have been carried out to look at the safety of the vaccines that are used in pregnancy and they were all proven to be safe. Certain vaccines cannot be used in pregnancy. Some vaccines contain live versions of the disease-causing organism, and these cannot be used for maternal immunization. These live vaccines include those against measles, rubella, mumps, smallpox, and yellow fever, to name a few $[6,7]$.

\section{WHAT ABOUT FUTURE VACCINES?}

Will the new vaccines still being developed and tested today also be safe to use during pregnancy? Hopefully, many of them will! In addition to the three vaccines that are currently given during pregnancy, many more could be of value to the pregnant woman and her baby. For example, infection with respiratory syncytial virus (RSV) causes severe lung problems in young babies. There is currently no cure for RSV infection, but if an RSV vaccine could be used during pregnancy, it 
would be easier to fight this disease. You can probably think of other diseases for which maternal immunization might be important, such as Covid-19 and Zika virus disease.

\section{MOST PREGNANT WOMEN SHOULD GET MATERNAL IMMUNISATIONS!}

Vaccination has long been known to protect people against dangerous infectious diseases. Maternal immunization is a safe way to protect both the pregnant woman and her unborn baby against diseases like flu, tetanus, and whooping cough. The antibodies the unborn baby receives from the mother can persist even after birth and can often last until the child is old enough to receive his or her own vaccinations.

Many women are being vaccinated during pregnancy, but we still need more people to understand why maternal immunization is necessary. Many people, including health care workers, often think of vaccines as something primarily for children, and do not yet automatically associate vaccines with pregnant women. Therefore, it is important for public health officials to continue to organize campaigns to raise awareness of the importance of vaccination during pregnancy. As more health care workers and pregnant women begin to appreciate the value of maternal immunization, more women and babies will be protected from dangerous infectious diseases. The existing maternal vaccines, and new vaccines still in development, may help to improve the health of mothers and new-borns all over the world [8].

\section{AUTHOR CONTRIBUTIONS}

$\mathrm{MO}$ and $\mathrm{KM}$ were responsible for the writing of some of the sections. EL was responsible for the general structure of the article, the writing of sections, as well as the homogenization of the whole text.

\section{REFERENCES}

1. Kachikis, A., Eckert, L. O., and Englund, J. 2018. Who's the target: mother or baby? Viral Immunol. 31:184-94. doi: 10.1089/vim.2017.0135

2. Neunez, M., Goldman, M., Goldman, S., and Lambert, P. 2019. Vaccines, shots that protect you. Front. Young Minds 7:31. doi: 10.3389/frym.2019.00031

3. Maertens, K., Orije, M. R. P., Van Damme, P., and Leuridan, E. 2020. Vaccination during pregnancy: current and possible future recommendations. Eur. J. Pediatr. 179:235-42. doi: 10.1007/s00431-019-03563-w

4. Malek, A., Sager, R., and Schneider, H. 1994. Maternal-fetal transport of immunoglobulin $\mathrm{G}$ and its subclasses during the third trimester of human pregnancy. Am. J. Reprod. Immunol. 32:8-14. doi: 10.1111/j.1600-0897.1994. tb00873.x 
5. Leuridan, E., Hens, N., Hutse, V., leven, M., Aerts, M., and Van Damme, P. 2010. Early waning of maternal measles antibodies in era of measles elimination: longitudinal study. BMJ 340:c1626. doi: 10.1136/bmj.c1626

6. Vilajeliu, A., Ferrer, L., Munrós, J., Goncé, A., López, M., Costa, J., et al. 2016. Pertussis vaccination during pregnancy: antibody persistence in infants. Vaccine 34:3719-22. doi: 10.1016/j.vaccine.2016.05.051

7. McHugh, L., Marshall, H. S., Perrett, K. P., Nolan, T., Wood, N., Lambert, S. B., et al. 2019. The safety of influenza and pertussis vaccination in pregnancy in a cohort of Australian mother-infant Pairs, 2012-2015: the FluMum study. Clin. Infect. Dis. 68:402-8. doi: 10.1093/cid/ciy517

8. McMillan, M., Clarke, M., Parrella, A., Fell, D. B., Amirthalingam, G., and Marshall, H. S. 2017. Safety of tetanus, diphtheria, and pertussis vaccination during pregnancy: a systematic review. Obstet. Gynecol. 129:560-73. doi: 10.1097/ AOG.0000000000001888

SUBMITTED: 29 July 2020; ACCEPTED: 20 April 2021; PUBLISHED ONLINE: 25 May 2021.

EDITED BY: Michel Goldman, Institute for Interdisciplinary Innovation in healthcare (I3h), Belgium

CITATION: Maertens K, Orije M and Leuridan E (2021) Vaccination of Pregnant Women: Protecting Babies Even Before Birth! Front. Young Minds 9:588591. doi: 10.3389/frym.2021.588591

CONFLICT OF INTEREST: The authors declare that the research was conducted in the absence of any commercial or financial relationships that could be construed as a potential conflict of interest.

COPYRIGHT (C) 2021 Maertens, Orije and Leuridan. This is an open-access article distributed under the terms of the Creative Commons Attribution License (CC BY). The use, distribution or reproduction in other forums is permitted, provided the original author(s) and the copyright owner(s) are credited and that the original publication in this journal is cited, in accordance with accepted academic practice. No use, distribution or reproduction is permitted which does not comply with these terms.

\section{YOUNG REVIEWER}

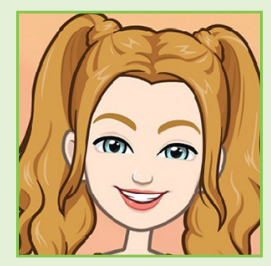

\section{LILI, AGE: 10}

$\mathrm{Hi}$, I am Lili. I love nature and I really enjoy going out and investigating wildlife. I am keen on biology and I have even visited a research laboratory. I am also fond of painting and I have won several art competitions where I had to draw wildlife. I am trying to do everything to protect the environment. In the future, I would like to write a book about helping the environment and I would also like to study at a veterinary college. 


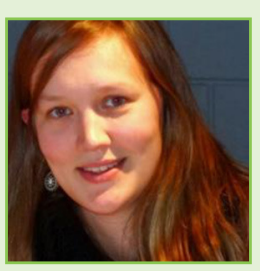

\section{AUTHORS}

\section{KIRSTEN MAERTENS}

I am a post-doctoral researcher at the Centre for the Evaluation of Vaccination at the University of Antwerp in Belgium. My research focuses on all aspects of vaccination in pregnancy including immune responses in both pregnant women and infants, the safety of vaccinating pregnant women, coverage and acceptance of this vaccination strategy in pregnant women... This research is very important to be able to improve current recommendations for vaccination in pregnancy and to develop new and better vaccines that can be used during pregnancy in order to offer better protection to pregnant women and newborns against infectious diseases.

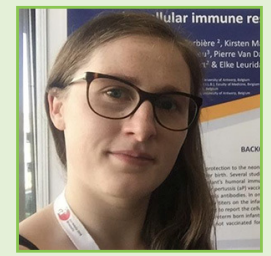

\section{MARJOLEIN ORIJE}

Marjolein R. P. Orije graduated in 2016 at the University of Antwerp as a major in Biomedical science. Afterwards, she has been working as a Ph.D. fellow on the topic of maternal immunization at The Center for the Evaluation of Vaccination.

\section{ELKE LEURIDAN}

Dr. Elke Leuridan is a Professor at the Vaccine \& Infectious Diseases Institute, Centre for the Evaluation of Vaccination, University of Antwerp, Belgium. She is a Medical Doctor and obtained a Ph.D. at the University of Antwerp, working on vaccine preventable diseases and maternal antibodies. She supervises several projects on all aspects of (pertussis) vaccination during pregnancy in Belgium and abroad (Vietnam, Thailand). She is member of the Belgian National Health Council, working group vaccination, and participates in the decision-making process on current and future immunization programs in Belgium. She combines working in research with general practice. *elke.leuridan@uantwerp.be 